\title{
ACIDENTES DE TRABALHO E DOENÇA OCUPACIONAL: ESTUDO SOBRE O CONHECIMENTO DO TRABALHADOR HOSPITALAR DOS RISCOS À SAÚDE DE SEU TRABALHO*
}

\author{
Beatriz Rosana Gonçalves de Oliveira** \\ Neide Tiemi Murofuse***
}

OLIVEIRA, B.R.G.de; MUROFUSE, N.T. Acidentes de trabalho e doença ocupacional: estudo sobre o conhecimento do trabalhador hospitalar dos riscos à saúde de seu trabalho. Rev.latino-am.enfermagem, Ribeirão Preto, v. 9, n. 1, p. 109-115, janeiro 2001.

Este estudo busca levantar o conhecimento dos trabalhadores de saúde hospitalar quanto a sua própria saúde no desenvolvimento de suas atividades. Foi realizado em um hospital geral, de médio porte, com serviço de medicina ocupacional funcionante. O caminho percorrido é a apresentação do objeto em estudo e a fundamentação teórica como forma de embasar a análise dos dados, colhidos através de um formulário com questões norteadoras e agrupados por categorias de análise, com a finalidade de apreender o saber do trabalhador sobre a relação trabalho-saúde-doença. O resultado evidenciou conhecimento genérico dos trabalhadores acerca da prevenção de acidentes e doenças ocupacionais.

UNITERMOS: trabalhadores, hospitais, saúde ocupacional

\section{INTRODUÇÃO}

$\boldsymbol{E}_{\text {ste trabalho busca levantar o conhecimento dos }}$ trabalhadores de saúde hospitalar quanto a sua própria saúde no desenvolvimento de suas atividades. A escolha da temática deu-se em função de que o trabalhador que presta assistência em saúde, direta ou indiretamente, demonstra preocupar-se muito com o cuidado do cliente e pouco com os riscos a que está exposto ao prestar este cuidado. A área escolhida foi a hospitalar, por apresentar maior variedade de riscos de acidentes e doenças ocupacionais, em relação as demais atividades de saúde. O campo de estudo foi um hospital geral, privado, de médio porte, com atividade terapêutica nas quatro clínicas básicas de atenção à saúde hospitalar e com exposição a diversos riscos ambientais, físicos e mentais, com serviço de medicina ocupacional funcionante. Buscamos neste ambiente saber o que os profissionais, que desenvolvem atividades no cotidiano do hospital, conhecem a respeito de precauções para evitar acidentes de trabalho e ou doenças ocupacionais, o que entendem por segurança e medicina do trabalho, às quais doenças ocupacionais pensam estarem sujeitos e a que tipos de acidentes de trabalho consideram-se expostos. O caminho percorrido no trabalho é a apresentação do objeto em estudo e a fundamentação teórica como forma de embasar a análise dos dados, colhidos através de um instrumento com quatro questões norteadoras, cujas respostas foram categorizadas em quatro grupos de interesse, com a finalidade de apreender o saber do trabalhador sobre a relação trabalhosaúde-doença. A instituição forneceu autorização formal para realização do estudo e dele participaram os entrevistados que concordaram em fazer parte do mesmo, após conhecerem o instrumento e o objetivo da pesquisa.

\section{BREVE HISTÓRICO DA ATENÇÃO À SAÚDE DO TRABALHADOR}

A doença ocupacional, embora ainda sem esta

\footnotetext{
* Trabalho Monográfico apresentada à FISC/CEDAS para obtenção do título de Especialista em Enfermagem do Trabalho no ano de 1996

** Enfermeira, Especialista em Enfermagem do Trabalho e em Enfermagem em Saúde Pública, Mestranda em Enfermagem Fundamental na Escola de Enfermagem de Ribeirão Preto da Universidade de São Paulo, docente do Curso de Enfermagem da UNIOESTE. Endereço: Rua: Paraná, 2059 - Ap. 152 - 85802-840 - Cascavel - Paraná - Brasil

*** Enfermeira, Especialista em Metodologia do Ensino Superior e em Iniciação a Pesquisa Científica. Mestranda em Enfermagem Fundamental na Escola de Enfermagem de Ribeirão Preto da Universidade de São Paulo, docente do Curso de Enfermagem da UNIOESTE
} 
denominação, é descrita desde tempos remotos. Hipócrates descreveu o quadro clínico da intoxicação saturnina, Plínio, o aspecto dos trabalhadores expostos ao chumbo, ao mercúrio e a poeiras, Agrícola escreve sobre a "asma dos mineiros", hoje denominada silicose e Paracelso, a intoxicação pelo mercúrio. Quase dois séculos mais tarde, em 1700 foi publicado "De Morbis Artificum Distriba", escrito por Bernardino Ramazzini, conhecido como "Pai da Medicina do Trabalho", descrevendo doenças de aproximadamente 50 ocupações $\left(\right.$ MENDES $^{22}$ ).

A "Revolução Industrial" (1760 - 1850) teve papel de destaque na mudança das condições de vida social e de trabalho. As condições de trabalho eram péssimas, as doenças e os acidentes eram numerosos, não havia limites na jornada, ultrapassando dezesseis horas de trabalho por dia, o ambiente era fechado e as máquinas sem qualquer proteção. Além disso, disseminaram-se também as doenças infecto-contagiosas (MENDES ${ }^{22}$ ).

Em 1831, uma comissão de inquérito chefiada por Michael Saddler, elaborou um relatório que chocou a opinião pública por suas conclusões. Em função do impacto deste relatório, em 1833, foi baixado o Factory Act - a primeira legislação realmente eficiente no campo da proteção ao trabalhador. No Brasil, a esse respeito, foram feitos estudos por RODRIGUES ${ }^{28}$; DEAN ${ }^{9}$; FAUSTO ${ }^{13}$, entre outros. Em 1919, foi aprovada a primeira lei sobre Acidentes do Trabalho (Decreto - legislativo $n^{\circ} 3.724$, de 15 de janeiro de 1919), sem contudo ser votado, o Código do Trabalho, proposto em 1917 ao congresso.

Os organismos internacionais - Organização Internacional do Trabalho (OIT) e Organização Mundial da Saúde (OMS) - deram importante contribuição no fortalecimento da medicina do trabalho. De uma comissão mista destes dois organismos, nasce em 1950 a definição dos objetivos da medicina do trabalho e a Recomendação $\mathrm{n}^{\mathrm{o}}$ 112, do OIT (1959), definindo objetivos e funções dos serviços médicos nos estabelecimentos de trabalho. Com base nesta Recomendação, na década de 70, o governo brasileiro regulamenta a obrigatoriedade dos serviços de segurança e medicina do trabalho, nas empresas acima de determinado porte e grau de risco (ROCHA et al. ${ }^{27}$ ).

A saúde do trabalhador, no pensamento clássico da medicina ocupacional, era entendida como relacionada apenas ao ambiente físico, na medida em que o trabalhador está em contato com agentes químicos, físicos e biológicos que lhe causem acidentes e enfermidades. Ganhou novo enfoque, a partir da década de 80 , no contexto da transição democrática, e em sintonia com o que ocorreu no mundo ocidental (MENDES \& DIAS ${ }^{21}$ ). Esse novo enfoque expressou-se nas discussões da VIII Conferência Nacional de Saúde, na realização da I Conferência Nacional de Saúde dos Trabalhadores, e foi decisivo para a mudança estabelecida na nova
Constituição Federal de 1988 (MENDES ${ }^{22}$ ).

O objeto da saúde do trabalhador pode ser definido como o processo saúde e doença dos grupos humanos, em sua relação com o trabalho. Trabalho entendido enquanto espaço de dominação e submissão do trabalhador pelo capital, mas, igualmente, de resistência, de constituições e do fazer histórico dos trabalhadores, que buscam o controle sobre as condições e os ambientes de trabalho, para torná-los mais saudáveis, num processo lento, contraditório, desigual no conjunto da classe trabalhadora, dependente de sua inserção no processo produtivo e do contexto sócio-político de uma determinada sociedade. Nesse sentido, a saúde do trabalhador aparece enquanto uma prática social instituinte e instituída dentro de um determinado modo de produção (ALESSI et al. ${ }^{2}$ ).

Nesta perspectiva, LAURELL ${ }^{15}$ coloca que o trabalho, como categoria social, está sujeito a múltiplos condicionantes. As condições de trabalho e suas patologias estão relacionados a outras variáveis, tais como a organização do trabalho e refletem valores e regras da sociedade.

Fica, portanto, difícil falar de um mundo do trabalho, e um mundo fora do trabalho. O mundo é um só, e os trabalhadores existem no mundo, transformando e por ele sendo transformados, com um modo de viver determinado historicamente, definido socialmente e diferenciado em classes sociais. É através do trabalho que o indivíduo se constitui como sujeito, afirmando sua identidade e seu desejo de ser reconhecido socialmente.

\section{BUSCANDO COMPREENDER ALGUMAS QUESTÕES SOBRE RISCOS À SAÚDE DO TRABALHADOR HOSPITALAR}

Para que consigamos entender a estrutura do trabalho de saúde hospitalar e chegarmos especificamente as condições de trabalho e riscos que daí advém, precisamos fundamentar historicamente a condição deste trabalho na sociedade capitalista.

A passagem da produção para o mercado do trabalho assalariado representa a passagem da independência à dependência. A passagem da elaboração completa do produto - base do orgulho profissional, à contribuição parcial e fragmentária, pode trazer tãosomente a sensação de insignificância. A passagem, enfim, do domínio do processo de trabalho em sua totalidade à inserção no seio de uma organização estruturada em torno de um poder hierárquico, alheia o trabalhador $\left(\right.$ ENGUITA $\left.^{12}\right)$.

O processo de trabalho da saúde, aplica modelos de sistematização de assistência que não encerra somente 
uma questão funcional e operacional, mas está todo carregado das relações sociais que se estabelecem no interior do trabalho da saúde, onde há uma hierarquização de poderes das categorias profissionais. $\mathrm{O}$ trabalho na saúde se dá coletivamente, com uma hierarquia de poder prévia e historicamente estabelecida, que é dada socialmente, entre médico e demais trabalhadores. No momento, as ações individuais de saúde estão mais fortalecidas e sendo mais executadas que as ações coletivas, embora a preconização teórica seja de regionalização, hierarquização, universalização, eqüidade, integralidade da assistência em saúde, no nível de atenção primária, num modelo de saúde coletiva, tendo a epidemiologia como paradigma (ALESSI et al. ${ }^{2}$; MACHADO et al. ${ }^{19}$ ).

O processo de trabalho na saúde evoluiu de forma que, de cuidados simplificados, passamos a trabalhar com instrumentos muito complexos, havendo a necessidade de diversificação e especialização da força de trabalho. As alterações tecnológicas ocorridas no trabalho em saúde, embora implicando, de um lado, em um processo mais coletivo, na medida em que as tarefas de um grupo profissional dependem de outro, tem tido como conseqüência, por outro lado, uma concentração das atividades reflexivas e de maior autonomia em apenas alguns grupos profissionais, permanecendo uma proporção cada vez maior de trabalhadores com atividades meramente rotineiras e padronizadas (SIQUEIRA et al. ${ }^{29}$ ).

A análise das condições de trabalho do trabalhador hospitalar revestem-no de características específicas, pois além de se relacionar com a doença e com a morte, é parte de um sistema que assegura a continuidade da produção e determina a quebra da continuidade no trabalho realizado individualmente, o que define o trabalho por turnos. Estudos $\left(\right.$ ALVES $\left.^{4,5}\right)$ realizados com estes trabalhadores evidenciam que as jornadas rotativas causam alterações do sono, distúrbios nervosos e digestivos, além de desorganizarem a vida familiar e social dos trabalhadores. Especialmente para o serviço de enfermagem, correspondente ao maior número de trabalhadores hospitalares na instituição alvo (51\%), a exposição a fatores de risco mecânicos e ambientais específicos, é ainda agravada pelos recursos materiais insuficientes e inadequados, que ocasionam condições inseguras no trabalho.

O estudo sobre as condições de saúde desse grupo profissional, deve levar em consideração a complexidade das relações entre saúde e trabalho, que extrapolam a visão tradicional da saúde ocupacional, restrita ao trabalho industrial e à uma visão limitada ao ambiente de trabalho.

Do ponto de vista estrito, os agravos à saúde relacionados ao trabalho são classificados em dois grupos: no primeiro, incluem-se aqueles que traduzem ruptura abrupta do equilíbrio entre as condições e o ambiente de trabalho e a saúde do trabalhador, como os acidentes do trabalho e as intoxicações agudas de origem profissional. O segundo grupo inclui agravos de caráter crônico: a doença profissional típica, definida como aquela inerente ou peculiar a determinado ramo de atividade $\left(\mathrm{MENDES}^{22}\right)$.

Um outro grupo é constituído pelas “doenças relacionadas com o trabalho" definidas pela Organização Mundial de Saúde como "agravos outros que, em adição a doenças profissionais legalmente desconhecidas, ocorrem em trabalhadores quando o ambiente ou condições contribuem significativamente para a ocorrência de doenças, porém em graus variados de magnitude (ABRASCO ${ }^{1}$ )".

Pode-se, ainda, mencionar grupos de problemas atribuídos à organização do trabalho no modo de produção capitalista, discutidos por autores como DEJOURS $^{10}$ e LAURELL \& NORIEGA ${ }^{16}$, como o envelhecimento precoce, a síndrome da fadiga patológica, os distúrbios do sono e da sexualidade, o estresse crônico.

Relacionamos ainda os agentes que causam riscos à saúde dos trabalhadores e que costumam estar presentes nos locais de trabalho, agrupados em: agentes químicos, agentes físicos, agentes biológicos, agentes ergonômicos e riscos de acidentes, segundo a legislação $\left(\right.$ ATLAS $\left.^{6}\right)$. Como fatores de penosidade para os trabalhadores hospitalares, Tonneau apud SIQUEIRA et al. ${ }^{29}$ coloca a carga mental, decorrente de memorização complexa, parcelamento do trabalho e esclarecimentos insuficientes e a carga psíquica, decorrente da pressão de concentração do trabalho, pressão das mudanças nas condições de risco do paciente e do confronto com o sofrimento.

Buscamos demonstrar para o ambiente hospitalar, algumas funções com os riscos inerentes ao desenvolvimento destas atividades $\left(\right.$ MENDES $^{22}$; BULHÕES $^{8}$; ALVES $^{4}$; MARZIALE \& ROZESTRATEN ${ }^{20}$; ALEXANDRE \& ANGERAMI ${ }^{3}$; MACHADO \& GOMES $^{18}$; LOPES et al. $^{17}$; LACAZ $^{14}$; SIQUEIRA et al. ${ }^{29}$; ROBAZZI ${ }^{26}$ et al.):

- serviço de enfermagem: contato com substâncias, compostos ou produtos químicos em geral, risco biológico permanente, esforço físico, levantamento e transporte manual de peso, postura inadequada, trabalho noturno, situações causadoras de estresse psíquico, na maioria das vezes arranjo físico inadequado, materiais inadequados ou defeituosos, iluminação inadequada;

- auxiliares de limpeza: contato com substâncias, compostos ou produtos químicos em geral, risco biológico permanente, esforço físico, levantamento e transporte manual de peso, postura inadequada, trabalho noturno, situações causadoras de estresse psíquico, na maioria das vezes arranjo físico inadequado, materiais inadequados ou defeituosos, iluminação inadequada, contato com lixo hospitalar; 
- auxiliares de lavanderia: contato com substâncias, compostos ou produtos químicos em geral, risco biológico permanente, esforço físico, levantamento e transporte manual de peso, postura inadequada, trabalho noturno, situações causadoras de estresse psíquico, na maioria das vezes arranjo físico inadequado, materiais inadequados ou defeituosos, iluminação inadequada;

- pessoal de cozinha e copa: exposição ao calor, trabalho noturno, máquinas e equipamentos sem proteção, arranjo físico inadequado, materiais inadequados ou defeituosos, probabilidade de incêndio ou explosão;

- auxiliares de costura: postura inadequada, monotonia e repetitividade, iluminação inadequada;

- auxiliar de farmácia e almoxarifado: levantamento de peso, postura inadequada, arranjo físico inadequado;

-serviços de escritório (recepcionista, secretária, auxiliar de escritório, digitador, office-boy, escriturário, etc.): iluminação deficiente, postura inadequada, lesões por esforços repetitivos - L.E.R., monotonia e repetitividade; - técnicos de RX: exposição a radiação.

Nosso objetivo ao descrever riscos destas atividades hospitalares é fundamentar os dados da pesquisa, que envolve os trabalhadores de maneira geral de um hospital de médio porte, sem especificar ou salientar nenhuma das atividades em detrimento de outras, visto que buscamos compreender qual a responsabilidade dos profissionais de saúde hospitalar, quanto a sua própria saúde. Entendemos como profissionais de saúde hospitalar aqueles citados anteriormente. Há outros ainda que não abordamos, pois a realidade estudada não os contempla.

\section{MATERIAL E MÉTODO}

A realização do estudo deu-se em uma instituição hospitalar localizada na cidade de Cascavel - PR, que atende as quatro clínicas básicas de atenção à saúde hospitalar, de capital privado e com fins lucrativos, com 52 leitos funcionais, sendo 42 destes conveniados ao Sistema Único de Saúde e o restante destinado ao atendimento de convênios e atendimentos particulares. A instituição conta com um contingente humano de 92 trabalhadores que desempenham diferentes funções, em serviços como o de enfermagem, lavanderia, cozinha, zeladoria, manutenção, administrativos, laboratoriais, entre outros. Desses trabalhadores 51\% desempenham atividades de enfermagem - enfermeiros e auxiliares de enfermagem - e todos, de maneira geral, vivenciam as situações de risco descritas anteriormente. Os profissionais médicos não foram incluídos na população de estudo uma vez que não tem vínculo empregatício com a instituição, sendo apenas prestadores de serviços.
Para esse estudo foram consideradas todas as unidades da empresa, num total de 24 , a população de estudo foi a totalidade (92 funcionários) dos trabalhadores, sendo os dados coletados por meio de um instrumento, com as seguintes questões norteadoras: Você sabe quais as precauções a tomar no sentido de evitar acidentes de trabalho e/ou ocupacionais? O que você entende por Segurança e Medicina do Trabalho? Quais os acidentes de trabalho que podem lhe acontecer? Quais as doenças ocupacionais a que você está exposto?

Foi solicitado formalmente autorização à instituição para a realização do estudo e individualmente a cada participante. Os formulários foram entregues aos participantes que o preencheram e devolveram posteriormente. Para agrupamento dos dados as respostas foram categorizadas por questão norteadora.

\section{APRESENTAÇÃO, ANÁLISE E DISCUSSÃO DOS DADOS}

Em relação a questão "Você sabe quais as precauções a tomar no sentido de evitar acidentes de trabalho e doenças ocupacionais", obtivemos os seguintes resultados: $32,61 \%$ fazem referência de forma direta ou indireta ao uso de equipamentos de proteção individual, como precaução para evitar acidentes de trabalho ou doenças ocupacionais. As respostas que denotam cuidados gerais totalizam $14,13 \%$ e incluem prestar atenção nas atividades que realiza, lavagem das mãos antes de qualquer procedimento, preparar medicações com atenção, ter princípios de assepsia, cuidar para não escorregar usando calçados apropriados, entre outros. $8,7 \%$ das respostas referem-se ao treinamento por parte da empresa no sentido de evitar os acidentes e doenças ocupacionais.

Parece-nos que o conhecimento do trabalhador hospitalar em relação a sua saúde, especificamente na abordagem acidente do trabalho e doenças profissionais, pode ser considerado como uma forma de atenção primária em saúde ocupacional, e de conhecimento de um número expressivo de trabalhadores. Contudo, as respostas encontradas levam-nos a crer que, embora o profissional de saúde promova o cuidado ao indivíduo doente, pouco sabe a respeito de cuidar de sua própria saúde profissional, pois a preocupação destes trabalhadores com sua saúde é genérica, na relação saúde - trabalho - doença.

Em relação a "o que você entende por segurança e medicina do trabalho"? apenas 41 dos 92 entrevistados responderam, o que representa $26,09 \%$. Consideramos tal dado como um percentual significativo de ausência de expressão do conhecimento, pois apenas esta questão 
do formulário não foi totalmente respondida. Somado ao número $(13,04 \%)$ de trabalhadores que responderam ignorar o que seja segurança e medicina do trabalho, temos um valor significativo de desconhecimento do Serviço Especializado em Segurança e Medicina do Trabalho - SESMT. Por outro lado, alguns funcionários conseguiram citar algumas atribuições deste serviço, como realização de exames periódicos e prevenção de risco no ambiente de trabalho e prevenção de acidentes, contradizendo a informação de outros, que referiram como sendo a constituição de Comissão Interna de Prevenção de Acidentes - CIPA. Parece-nos existir alguma compreensão do que seja o serviço em questão entre os funcionários, porém, fragmentada e dicotomizada, necessitando ainda de informações para ter uma noção mais abrangente do SESMT. Nesse sentido, traçamos alguns comentários sobre a atenção à saúde dos trabalhadores.

Enquanto prática social a saúde do trabalhador apresenta dimensões sociais, políticas e técnicas, indissociáveis, que marcam sua ação e respondem pela ruptura com a concepção hegemônica que estabelece um vínculo causal entre a doença e um agente específico, ou a um grupo de fatores de risco presentes no ambiente de trabalho e tenta superar o enfoque que situa sua determinação no social, reduzindo ao processo produtivo, desconsiderando a subjetividade (DIAS ${ }^{11}$ ).

Assim, a saúde do trabalhador apresenta expressões diferenciadas segundo a época, o país e dentro do próprio país, mantendo, porém, o mesmo princípio trabalhadores buscam ser reconhecidos em seu saber, questionam as alterações nos processos de trabalho, particularmente a adoção de novas tecnologias e novas formas de organizar o trabalho, exercitam o direito à informação e a recusa ao trabalho perigoso ou arriscado à saúde (BERLINGUER ${ }^{7}$; PARMEGGIANI ${ }^{24}$; ODDONE $^{23}$ et al.; RIGOTTO ${ }^{25}$ ).

Durante muito tempo, em decorrência da maneira fragmentada de ver o mundo, conivente/conveniente ao desenvolvimento da sociedade capitalista, procurou-se atribuir ao trabalhador a responsabilidade por sua saúde ou por sua doença, através do ideário do risco iminente, e portanto de doenças inerentes a determinadas profissões. A desmistificação dessa idéia tem exigido um grande esforço de todos aqueles que se empenham na mudança desta situação.

Em relação a terceira questão "quais os acidentes de trabalho que podem the acontecer?" $31,52 \%$ referemse as lesões físicas e aos possíveis acidentes, as causas de ferimentos por pesos, intoxicações, doenças infectocontagiosas, queimaduras, contaminação. 17,3\% referemse aos materiais pérfuro-cortantes, risco característico do ambiente hospitalar, e 13,09\% das pessoas descreveram os riscos físicos, químicos e ergonômicos.
A quarta questão refere-se a "quais as doenças ocupacionais a que você está exposto"?, onde se obteve respostas que podem ser divididas em dois blocos: o primeiro $(39,08 \%)$ com ênfase na preocupação de se adquirir um tipo qualquer de doença infecto-contagiosa e o segundo $(15,14 \%)$ voltado à ocupação propriamente dita.

Poderíamos ter considerado apenas as respostas do segundo bloco como doença ocupacional propriamente dita e argumentar que a grande maioria das doenças referidas $(39,08 \%)$ do primeiro bloco, dão-se após um ferimento causado por acidente de trabalho ou por respostas a doenças do sistema imunológico ${ }^{14}$ e outras, mas preferimos considerá-las também como doenças ocupacionais, pois, segundo BULHÕES ${ }^{8}$, os agentes biológicos -microorganismos e parasitas infecciosos vivos e seus produtos - são agentes patogênicos de doenças profissionais.

MENDES $^{22}$ refere-se aos agentes biológicos, destacando as infecções virais, com agravante a trabalhadora gestante, refere a Hepatite B, HIV, Cytomegalovirus (C.M.V.) Rubéola, Parvoviroses Humanas e Varicela, descreve ainda a exposição ocupacional em ambiente hospitalar às hepatites virais, principalmente a Hepatite "A", a Hepatite "B" e Hepatite "C".

BULHÕES $^{8}$ descreve como principais infecções, a que está sujeito o trabalhador da saúde, a Hepatite B e tuberculose pulmonar, Cytomegalovirus (C.M.V.), H.I.V. e colocou também a exposição a outras infecções como rubéola, meningite, difteria, herpes simples, varicela zoster (herpes zoster), febre tifóide, gastroenterite infecciosa, parotidite, queratoconjuntivite epidêmica e infecções respiratórias por vírus citando ainda as doenças causadas por bactérias envolvidas nas infeções hospitalares: Staphylococcus aureus, E. Coli, Salmonellas, Streptococcus, Pseudomonas, Proteus. Aponta ainda a AIDS e apesar de referir serem baixos os riscos de infecção profisssional pelo H.I.V., recomenda as mesmas medidas preventivas indicadas contra a Hepatite B, ou seja, cuidados com todos os fluidos corporais de todos os doentes.

Avaliando-se as respostas do segundo bloco, compreendendo o que ocorre no dia a dia hospitalar, os esforços de auxilio ao paciente com dificuldade de locomoção e até de levantar-se do leito, a passagem de macas ao leito e vice-versa, os períodos de jornadas, os horários noturnos, iluminação artificial predominante, deambulação com posições viciosas, movimentos repetitivos etc., justificam perfeitamente as resposta de lombalgias (coluna), problemas de visão e outros.

Observamos que as respostas obtidas estão em linha com a literatura consultada, traduzindo como bastante real, embora genérica, a preocupação do trabalhador da área de saúde. 


\section{RESULTADOS DO ESTUDO}

$\mathrm{O}$ resultado mostrou que os trabalhadores de saúde conhecem os riscos à sua saúde de uma forma genérica. Percebeu-se que o conhecimento demonstrado é fruto da prática cotidiana e não oriundo da existência de um serviço de saúde ocupacional na instituição. Esse conhecimento, entretanto, não se transforma numa ação segura de prevenção de acidentes e doenças ocupacionais, apontando para a necessidade de uma atuação que venha a modificar essa situação. Representa um esforço de compreensão deste processo - como e porque ocorre - e desenvolvimento de alternativas de intervenção que levam a transformação em direção à apropriação pelos trabalhadores da dimensão humana do trabalho.

Assim podemos dizer que permanece o desafio de garantir que os avanços citados, entre eles a atenção a saúde dos trabalhadores pelo SUS, saiam definitivamente do papel e sejam incorporados, de fato, ao cotidiano dos trabalhadores de um modo geral e em particular dos trabalhadores da saúde.

\section{LABOUR ACCIDENTS AND OCCUPATIONAL SCKNESS: STUDY ABOUT THE KNOWLEDGE DEGREE OF THE HOSPITALAR WORKER IN A PRIVATE HOSPITAL}

This study searches to gather the knowledge of the hospitalar health workers in relationship their own health in the development of their activities. The study was accomplished in a general hospital, of medium load, with medicine service occupational functioning. The way gone through is the presentation of the subject in study and the theoretical foundation as a way of basing the analysis of the datas, gathered through the questionaire, to apprehend the worker's knowledge about the relationship work-health-disease. The result evidenced the workers'generic knowledge concernig the prevention of accidents and occupational diseases.

KEY WORDS: worker, hospital, occupational health

\section{ACCIDENTES DE TRABAJO Y ENFERMEDAD OCUPACIONAL: ESTUDIO SOBRE EL CONOCIMIENTO DEL TRABAJADOR HOSPITALARIO, EN RELACIÓN CON LOS RIESGOS DE SU TRABAJO PARA LA SALUD}

Este estudio busca levantar el conocimiento de los trabajadores de salud hospitalaria en relación con su propia salud en el desarrollo de sus actividades. Fue realizado en un hospital general de medio porte, con servicio de medicina ocupacional en funcionamiento. El camino recorrido es la presentación del objeto en estudio y la fundamentación teórica como forma de sustentar el análisis de los datos recogidos a través de un formulario con preguntas orientadoras y agrupadas por categorías de análisis, con la finalidad de aprehender el saber del trabajador sobre la relación trabajo-salud-enfermedad. El resultado evidenció conocimiento genérico de los trabajadores acerca de la prevención de accidentes y enfermedades ocupacionales.

TÉRMINOS CLAVES: trabajadores, hospitales, salud ocupacional

\section{REFERENCIAS BIBLIOGRÁFICAS}

01. ABRASCO. ASSOCIAÇÃO BRASILEIRA DE SAÚDE COLETIVA. Saúde e trabalho: desafio para uma política. Rio de Janeiro: Abrasco, 1991.

02. ALESSI, N.P. et al. Saúde e trabalho no sistema único de saúde. São Paulo: Hucitec, 1994.

03. ALEXANDRE, N.M.C.; ANGERAMI, E.L.S. Estilo de vida e trabalho do pessoal de enfermagem e a ocorrência de cervicodorsolombalgias. Rev. Latino-am. Enfermagem, v. 3, n. 1, p. 117-136, 1995.

04. ALVES, D.B. Condições de trabalho na enfermagem: aspectos teóricos In: CONGRESSO BRASILEIRO DE ENFERMAGEM, 39, Salvador, 1987. Anais. Salvador: Organizador, 1988.
05. Mercado e condições de trabalho na enfermagem. Salvador: Gráfica Central, 1987.

06. ATLAS. Segurança e medicina do trabalho. 29. ed. São Paulo: Atlas, 1995.

07. BERLINGUER, G. A saúde nas fábricas. São Paulo: Hucitec, 1978.

08. BULHÕES, I. Riscos do trabalho de enfermagem. Rio de Janeiro, 1994.

09. DEAN, W. A industrialização de São Paulo: 13301945. Trad. Octavio Mendes Cajado. São Paulo: Difel, 1971.

10. DEJOURS, C. A loucura do trabalho: estudo de psicopatologia do trabalho. São Paulo: Oboré, 1987. 
11. DIAS, E.C. Evolução e aspectos atuais da saúde do trabalhador no Brasil. Bol. Of. Sanit. Panam., v. 115, n. 3, p. 202-214, 1993.

12. ENGUITA, M. F. A face oculta da escola: educação e trabalho no capitalismo. Porto Alegre: Artes Médicas, 1989.

13. FAUSTO, B. Trabalho urbano e conflito social: 1890 - 1920. Rio de Janeiro: Difel, 1977.

14. LACAZ, F. A. de C. Saúde dos trabalhadores: cenário e desafios. Cad. Saúde Pública, v. 13, n. 2, p. 719, 1997.

15. LAURELL, A.C. Saúde e trabalho: os enfoques teóricos. In: NUNES, E. D. (org.) As ciências sociais em saúde na América Latina: tendência e perspectivas. Brasília: OPAS, 1985.

16. LAURELl, A.C.; NORIEGA, M. Processo de produção e saúde: trabalho e desgaste operário. São Paulo: Hucitec, 1989.

17. LOPES, G.T.; SPÍNDOLA, T.; MARTINS, E.R.C. O adoecer em enfermagem segundo seus profissionais: estudos preliminares. Rev. Enfermagem UERJ, v. 4, n. 1, 9-18, 1996.

18. MACHADO, J. M. H.; GOMEZ, C.M. Acidentes de trabalho: concepções e dados. In: MINAYO, M.C.S. (org.) Os muitos Brasis: saúde e população na década de 80 . São Paulo/Rio de Janeiro : Hucitec/Abrasco, 1995.

19. MACHADO, M.H. (Org.) Profissões de saúde: uma abordagem sociológica. Rio de Janeiro: Fiocruz, 1995.
20. MARZIALE, M.H.P.; ROZESTRATEN, R.J.A. Turnos alternantes: fadiga mental de enfermagem. Rev. Latino-am. Enfermagem, v. 3, n. 1, p. 5978, 1995.

21. MENDES, R.; DIAS, E.C. Da medicina do trabalho à saúde do trabalhador. Rev. Saúde Pública, v. 25, n. 5, p. 341-349, 1991.

22. MENDES, R. Patologia do trabalho. Rio de Janeiro: Atheneu, 1995.

23. ODDONE, I. et al. Ambiente de trabalho: a luta dos trabalhadores pela saúde. São Paulo: Hucitec, 1986.

24. PARMEGGIANI, L. A nova legislação de segurança e saúde dos trabalhadores. Rev. Bras. Saúde Ocup., v. 15, n. 50, p. 19-27, 1985.

25. RIGOTTO, R. M. Não somos máquinas: práticas sindicais em saúde na região metropolitana de Belo Horizonte. Belo Horizonte, 1992. Dissertação (Mestrado) - Faculdade de Educação, Universidade Federal de Minas Gerais.

26. ROBAZZI, M.L.do C.C. et al. Serviço de enfermagem: um estudo sobre os absenteísmos. Rev. Bras. Saúde Ocup., n. 69, v. 18, p. 65-70, 1990.

27. ROCHA, L.E.; RIGOTTO, R.M.; BUSCHINELLI, J.T.P. Isto é trabalho de gente? vida, doença e trabalho no Brasil. Petrópolis, RJ: Vozes, 1994.

28. RODRIGUES, L.M. Conflito industrial e sindicalismo no Brasil. São Paulo: Difel, 1966.

29. SIQUEIRA, M.M.de; WATANABE, F.S.; VENTOLA, A. Desgaste físico e mental de auxiliares de enfermagem: uma análise sob o enfoque gerencial. Rev. latino-am. Enfermagem, v. 3, n. 1, p. 45-57, 1995. 